Políticas de vivienda

\title{
Arreglos neocorporatistas en la política habitacional. Un análisis de los Macroproyectos de Interés Social Nacional en Colombia
}

Neocorporatist Arrangements in the Habitational Policy. An Analysis of the Macroprojects of National Social Interest in Colombia

Acordos neocorporativistas na politica habitacional. Uma análise dos Macroprojetos de Interesse Social Nacional na Colômbia

Óscar A. Alfonso R.

Recibido: 23 de enero de 2018

Aprobado: 24 de abril de 2018

Doi: http://dx.doi.org/10.12804/revistas.urosario.edu.co/territorios/a.6449

Para citar este artículo:

Alfonso R. Ó. A. (2019). Arreglos neocorporatistas en la política habitacional. Un análisis de los Macroproyectos de Interés Social Nacional en Colombia. Territorios (40), 171-199. Doi: http://dx.doi.org/10.12804/ revistas.urosario.edu.co/territorios/a.6449

* Doctor en Planeamiento Urbano y Regional, Instituto de Pesquisa en Planeamiento Urbano y Regional, Universidad Federal de Rio de Janeiro, IPPUR/ UFRJ. Docente investigador, Universidad Externado de Colombia. Grupo de investigación Construcción de Estado, Territorio y Paz de la Facultad de Economía. Correo electrónico: oscar.alfonso@uexternado. edu.co ORCID: http://orcid.org/0000-0003-07810658.

Agradezco las criticasysugerencias de los dos árbitros anónimos de la revista Territorios. 
Palabras clave

Neocorportatismo, politica habitacional, crisis recesiva.

Keywords

Neo-corporatism, housing policy, recessionary crisis.

Palavras-chave

Neocorporativismo, politica habitacional, crise recessiva.

tersitarias 40

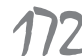

\section{RESUMEN}

El Estado contemporáneo tiene varias facetas. La del neocorporatismo es una forma moderna de representación de intereses que, en el caso de la política habitacional en Colombia, tomó cuerpo en un arreglo para producir suelo edificable con proyectos habitacionales para hogares pobres que enfrentó el impasse de la autonomía local en el ordenamiento territorial. La manera como se resolvió tal inconveniente es analizada con el empleo de una periodización ad hoc que pone de manifiesto que el arreglo neocorporatista de los Macroproyectos de Interés Social Nacional se produjo para enfrentar la crisis recesiva del sector constructor ocurrida en la coyuntura de 2008.

\section{ABSTRACT}

The contemporary state has several facets. The neo-corporatism is a modern form of representation of interests that, in the case of housing policy in Colombia, took shape in an arrangement to produce buildable land with housing projects for poor households that faced the impasse of local autonomy in territorial planning. The way in which this problem was solved is analyzed with the use of an ad hoc periodization that shows that the neo-corporatist arrangement of the macroprojects corresponding to the government Social Interest plan was produced to face the recessionary crisis in the construction sector that took place in the 2008 conjuncture.

\section{RESUMO}

O estado contemporâneo tem várias facetas. A do neocorporativismo é uma forma moderna de representação de interesses que, no caso da política habitacional na Colômbia, tomou corpos em um acordo para produzir solo edificável com projetos habitacionais para lares pobres que enfrentou o impasse da autonomia local no ordenamento territorial. A forma como se resolveu tal inconveniente é analisada com o emprego de uma periodização ad hoc que põe de manifesto que o acordo neocorporativista dos Macroprojetos de Interesse Social Nacional se produziu para enfrentar a crise recessiva do setor construtor ocorrida na conjuntura de 2008. 


\section{Introducción}

La cuestión habitacional es uno de los fenómenos más estudiados en las metrópolis del Tercer Mundo. Ella envuelve fenómenos de reconocida trascendencia socioeconómica y política como el déficit habitacional y sus manifestaciones más evidentes, como el hacinamiento, la informalidad urbana y las demandas de justicia espacial, la segregación residencial y la gentrificación, la financiarización y sus vínculos con las burbujas inmobiliarias y las crisis recesivas y su potencial económico anticíclico, entre otros. Este trabajo se inserta en este último fenómeno y, para ello, se asume como hipótesis que los Macroproyectos de Interés Social Nacional (MISN) son el resultado de un acuerdo que reviste las características señaladas por las corrientes analíticas del Estado neocorporatista. Este tipo de hipótesis se encamina a proponer vías de análisis de las políticas públicas en los que la naturaleza del Estado y sus relaciones con los grupos de interés hagan parte de las propuestas teóricas en que se soportan. El objetivo general es el análisis de un episodio particular de la política habitacional que surgió en una coyuntura económica crítica, a fin de comprender cómo la representación de intereses gremiales ocasiona un retroceso democrático duradero. La metodología parte de la elaboración de un contexto basado en la evolución de los costos de la construcción de vivienda y sus vínculos explicativos de la mencionada crisis, y de las conductas del gremio constructor, del Ministerio de
Vivienda y de la Corte Constitucional, a la luz de los documentos públicos asociados con el fenómeno.

Los estudios sobre el carácter corporatista de los Estados contemporáneos plantearon un vasto acervo de hipótesis acerca de sus transformaciones con un aspecto en común: la pérdida del pluralismo. Las corrientes neocorporatistas conservan la misma preocupación, pero aportan nuevos elementos de análisis sobre las relaciones con los heterogéneos grupos de interés surgidos en las últimas décadas. Este tránsito se discute en la primera parte como preámbulo a la exposición del devenir de la política habitacional en Colombia que se presenta en dos partes: la segunda que se ocupa del análisis de las políticas sobre el sector líder de la economía - la construcción de vivienda-, y la tercera en la que, con arreglo a una periodización construida a partir del comportamiento de los costos de la construcción residencial, se ubica a los MISN como un arreglo motivado en el interés de los miembros de la cadena productiva de sobreponerse a la crisis recesiva de 2008. Los resultados se comparan con los obtenidos recientemente con la política del Subsidio Familiar de Vivienda en Especie. Las reflexiones finales se acompañan con algunas líneas ulteriores de investigación.

\section{El tránsito del corporatismo al neocorporatismo}

Según Popper (2006), los paradigmas teóricos fenecen ante el surgimiento de otros con mayor poder explicativo de los territorias 40

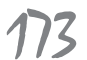


fenómenos de interés científico, de manera que la ciencia es como un campo de sobrevivientes que, por supuesto, no acostumbran visitar el cementerio de ideas sobre los que se ha erigido. Esta premisa se ha puesto en duda ante la resurrección del liberalismo con reconocida vehemencia bajo la forma del neoliberalismo, por ejemplo. El corporatismo yace al lado de otras corrientes de pensamiento que procuraron explicaciones a las conductas individuales y colectivas más complejas que las promulgadas por los enfoques convencionales de la elección y de las preferencias. Y fue sepultado después de múltiples ataques originados en diferentes frentes que tienen en común la creencia fáctica que el corporatismo no consigue explicar y tampoco ofrece alternativas a los retrocesos experimentados en materia de representación democrática (Audelo, s.f.). Pero el auge del corporatismo estatal antidemocrático y las renovadas demandas de derechos anuncian su renacimiento.

Los orígenes del corporatismo están asociados con el colapso del liberalismo y al ascenso del fascismo que, por su parte, resultó de la descomposición moral en Europa y del declive de sus valores en el tránsito de la Primera Guerra Mundial a la posguerra, periodo de profundas transformaciones sociológicas como que la vinculación con algún grupo trascendía sobre la condición de proletario o burgués, y las capas medias reclamaban una mayor participación en el poder (Visedo, 1996). Diversos segmentos de la sociedad se inclinaron por soluciones reaccionarias a problemas como la corrupción, el atraso económico, el predominio del caciquismo y las decisiones arbitrarias, las que eran ejecutadas por las facciones milanesas de los Fasci italiani di Combattimento (Visedo, 1996). Fue el corporatismo dirigista. Es en este contexto político en el que "el sistema corporativo hace que se borre la distinción entre poder político y poder económico; la negociación económica no se abandonó al mercado privado y los organismos del Estado pasaron a intervenir como activos mediadores" (Visedo, 1996, p. 70).

Pero, ha ocurrido una separación entre el fascismo y el corporatismo, no obstante que persistan tergiversaciones que los igualan. Según Panitch (1980), desde inicios de los años setenta, el corporatismo se emplea "como un término científico social aplicado a ciertos desarrollos o arreglos en sociedades capitalistas avanzadas contemporáneas" (p. 1). Entendido desde entonces como "un sistema distintivo y moderno de representación de intereses" (Schmitter, 1974, p. 85), fue previsto como la etapa del desarrollo del capitalismo subsiguiente al liberalismo del siglo XIX. Más recientemente, el debate sobre el Estado propuesto por los teóricos del corporatismo y del neocorporatismo ha girado sobre la manera como las autoridades públicas, esto es, el aparato de Estado, procesan las demandas de las organizaciones o grupos de interés inclinando la balanza de sus intervenciones hacia la satisfacción de estas. Esas organizaciones suelen ser de clase social, rama de actividad, profesión y de origen carismático, y son complejas en tanto su estructura interna 
y sus formas de actuación. En el caso de los gremios económicos, por ejemplo, no agrupan solamente a competidores con algún poder de mercado, sino que afilian a cada vez más miembros de la cadena productiva en que operan, a lo que Panitch (1980) denominó como "representación funcional" (p. 160). La institucionalización del Estado Social de Derecho no ha sido obstáculo para que ello ocurra y tiende a concebirse como un enunciado normativo con escasas repercusiones prácticas. La primacía del gasto social sobre cualquier otro emolumento estatal en un mundo en el que las demandas por el cumplimiento de los derechos se acrecientan, se diluye en un alud de aplazamientos y postergaciones que los formuladores de la regla fiscal se negaron a prever, y aún persisten en ello.

La premisa fundamental de la necesidad de otorgar el poder regulatorio al Estado y sus agencias, al aparato de Estado, es que la libertad económica no garantiza $y$, por el contrario, tiene un gran potencial para impedir el logro de la libertad política. Los teóricos neoclásicos de la elección pública y de la elección racional, así como los de la corriente denominada neoinstitucional que atribuye el surgimiento del Estado a la supuesta necesidad de reducir los costos de transacción (Bresser-Pereira, 2009), piensan todo lo contrario. Pero, mientras existan agencias regulatorias, también existen incentivos para que los empresarios persigan dentro de sus objetivos empresariales la captura del poder regulatorio del Estado, con tanto o más ahínco que la maximización de los be- neficios o el incremento en el poder de mercado. De manera complementaria, el erario se ha tornado en el blanco tanto de los más como de los menos eficientes. La soberanía estatal queda en entredicho por esas influencias de unos cuantos agentes mercantiles en detrimento de las aspiraciones sociales más universales.

La tendencia a la disolución de la unidad y coherencia del Estado y la contracción de sus principales órbitas funcionales, esto es, las de provisión de bienes y servicios de trascendencia social y las regulatorias de las fallas de los mercados, es en buena medida el resultado del triunfo de los defensores del Estado mínimo como supuesta vía para alcanzar la libertad política; no obstante, y de manera contradictoria, compiten por el control de aquellos lugares claves de orientación del erario. Organizaciones de intereses pululan y al adquirir reconocimiento público se adhieren como formuladores de políticas y detentores de la capacidad de intervención del disminuido Estado en alguna actividad, fenómeno estudiado por las corrientes neocorporatistas del Estado. El intercambio político entre el aparato de Estado y estas organizaciones no es igualitario, uniforme ni mucho menos pacífico.

Sostiene Schmitter (1985) que, salvo en escasas ocasiones:

los acuerdos neocorporatistas han sido en su mayor parte la salida no intencionada a una serie de conflictos de intereses y de crisis políticas en las que ninguno de los representantes involucrados de los grupos y de territarias 40

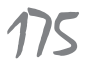


las clases sociales y del Estado fue capaz de imponer sus preferencias (p. 51).

Es decir, que, siguiendo a Panitch (1980), no hay sistemas corporatistas completos o absolutos. No obstante, la estructura económica es un factor decisivo para orientar el tipo de intercambios políticos. Por tanto, la matriz insumo producto de cada país, además de ser un instrumento para la planificación económica, también es un instrumento al servicio de la negociación política. Si existe un sector líder de la economía, caracterizado por tener el mayor número de eslabonamientos hacia atrás y hacia adelante, los agentes privados y sus organizaciones vinculadas a esa actividad gozan de un poder diferencial para negociar con el Estado. El bloque en el poder sabe que los resultados en materia de crecimiento económico y en el mercado de trabajo dependen en buena medida de lo que ocurra con el sector líder y, por tanto, estarán dispuestos a hacer concesiones regulatorias y diseñar mecanismos de estímulo para su crecimiento. El lobby es la práctica más generalizada para que las corporaciones se notabilicen ante el aparato de Estado, pero también como forma de gestión de sus pretensiones, $\mathrm{y}$ adquiere ribetes de ilegalidad cuando la eficacia de los lobistas consigue la omisión de la intervención estatal o la captura del regulador.

Los problemas surgen cuando los resultados privados no coinciden con las aspiraciones socio-espaciales, en buena medida como consecuencia de la heteronomía del Estado produciendo regulaciones y dise- ñando estímulos para grupos contradictorios. Uno de ellos es la incompatibilidad entre los fines perseguidos por regímenes democráticos tales como la autonomía y la soberanía de los tomadores de decisiones vinculantes y la escala producida y reproducida por organizaciones complejas y grupos económicos (Schmitter, 1999). A mayor escala, menos democracia. Los grupos económicos acostumbran tener nombre, voceros y hasta sede, pero las agencias regulatorias del Estado desconocen su composición y las ramificaciones de sus capitales, de manera que prácticas antidemocráticas como el comercio intrafirma, denominada de manera ampulosa como de 'solidaridad capitalista', eluden eficazmente la órbita regulatoria del Estado.

¿Cuáles son los intereses institucionales del Estado? Probablemente coincidan total o parcialmente con los de las clases dominantes, con los de los capitalistas que quieren que el sistema perdure, y menos con los de las organizaciones sociales que vindican la igualdad en el trato, la equidad en la provisión de bienes públicos y la garantía a los derechos fundamentales. No obstante, esos intereses comúnmente se mueven en una holgada banda, en donde las intenciones de los gobernantes son seguidas por los funcionarios públicos, por el aparato de Estado, en parte. Un gobernante electo que base su programa de gobierno en la lucha abierta y sin descanso contra la corrupción administrativa y, al final del mandato, puede encontrar que sus logros han sido magros o que, inclusive, la corrupción se incrementó. La respuesta 
debe buscarse entonces en las reglas para la conformación del aparato de Estado, entre las que la meritocracia siempre estará relegada a los lugares secundarios. Cuando esto ocurre, cuando los más capacitados e idóneos para conducir el Estado son marginados de los lugares claves de decisión, la noción de la elite se envilece, pues no son los mejores los que alcanzan el poder sino aquellos al servicio de la reproducción del modelo.

Hay un proceso de aprendizaje que, según Schmitter (1985), deviene de que "cualquier político que llegue al poder, o cualquier funcionario que tome posesión de su puesto, aprenderá rápidamente cuáles son los intereses del Estado y qué límites imponen a sus acciones" (p. 54). Ese proceso de aprendizaje tiene límites. El ancho de la banda del poder está delimitado, en principio, por los acuerdos interestatales, cuya tradición se remonta a la suscripción del Tratado de Westfalia en 1648, a partir del que se establece que la existencia de los Estados es inmanente a la integridad territorial de la que deviene la noción de la soberanía nacional. Son los Estados nacionales los únicos reconocidos para suscribir estos acuerdos. Adicionalmente, y con mayor intensidad en la era de la globalización, el afán competitivo ha llevado a adoptar estrategias nacionales para ganar espacio en los mercados mundiales. Esto ha conducido a que en los tratados de comercio los acuerdos sectoriales primen sobre los territoriales. Los gremios tienen más injerencia que las metrópolis o las regiones. El empleo de las medidas arancelarias y para-arancelarias para la protección de alguna rama de la actividad económica de la competencia externa, y el empleo ad hoc de complejos mecanismos de promoción de los bienes exportables, revela el interés de algunos nacionales pero no de los intereses nacionales. Las economías más competitivas, con mejores reglas y mayor dotación tecnológica, son menos propensas a este tipo de acuerdos que las peor dotadas (Schmitter, 1985).

Un sistema de conveniencias mutuas orienta el neocorporatismo. Revéiz (2016) establece que:

los cuasi-Estados, los Estados débiles y aquellos en que la cultura ciudadana se acomoda a los valores de la dirigencia corrupta han visto surgir un sutil y fino sistema de contratación ad hoc, paralelo al institucional, que se ha consolidado en el orden intermedio como mesocontrato, arrebatándole el espacio de aplicación a las leyes (p. 55).

El mesocontrato deriva en un "poder constituido paralelo" (Revéiz, 2016, p. 67), cuya longevidad depende de la tolerancia de los demás agentes del sistema, en el que el poder de cooptación del Estado se pone a prueba cuando las organizaciones de intereses se resisten a aparecer como meros subordinados de un poder superior $y$, por el contrario, perseguirán suscribir contratos del tipo "entre iguales" y no "de superior a inferior". Un mesocontrato es del primer tipo y surge generalmente debido a la degradación de la clase política que propicia el neocorporatismo, pues en las entrañas tersitarias 40

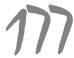


${ }^{1}$ Marques-Pereira es de los autores que persisten en emplear el término 'corporativismo', al igual que Ortega (1997) en su estado del arte. Solé (1984) otorga escasa importancia a la semántica, mientras que Schmitter (1985) dedica parte de sus reflexiones al empleo de la noción del corporatismo.

\section{territarias 40} 178 de esos pactos se erigen las nuevas fuentes de reproducción del sistema. Cuando la competencia intrasectorial anuncia la ruina de sus agentes, el neocorporatismo se presenta como un poderoso salvavidas, tal vez el único, para contener la debacle.

Una de las representaciones neocorporatistas más estudiadas es el gobierno de interés privado que ocurre cuando "una organización - con toda probabilidad monopolista - coloniza a un organismo particular del Estado y puede así hacer un uso privado de sus poderes públicos para dictar normas, conceder subsidios, etc." (Schmitter, 1985 , p. 60). Entre mayor sea la complejidad de la organización, su status será más elevado, dependiendo de este último la trascendencia y durabilidad de los acuerdos neocorporatistas. Esas organizaciones se asocian con el Estado y el no hacerlo las puede convertir en grupos de presión, tal como ocurre con aquellas organizaciones menos complejas cuyo status inferior no les ha permitido realizar acuerdos de alguna trascendencia político-económica. El cálculo político y las medidas anticipatorias o preventivas de las reacciones de los grupos de presión son cruciales al momento de operar el gobierno de interés privado y garantizar su éxito. Este cálculo no es posible sin que el cumplimiento del prerrequisito de que las organizaciones complejas ejercen el monopolio de la representación industrial y garantizan la disciplina de sus miembros (Schmitter, 1985, p. 68). En algunos países centrales, esta controversia se ha resuelto a partir de la 'democracia participativa gremial' (Kattan, 2013) con la que el Estado busca evitar la conformación de grupos de presión.

Una aguda controversia teórica se ha suscitado al respecto. La taxonomía según la cual hay un macro-corporatismo en el que las asociaciones de capitalistas y de trabajadores inciden en la planificación económica, el meso-corporatismo en el que la política industrial revela los intereses de profesionales sectoriales, y el micro-corporatismo en el que el interés es alguna empresa que es subvencionada, según Panitch (1988), es insuficiente para cientistas sociales como Cawson para quien la reconstrucción de la teoría política requiere de nuevas bases, a lo que se refiere como la llegada de la etapa del monopolio en la industria del corporatismo. Cawson (1988) replicó reafirmando cierto acuerdo con Panitch en cuanto a que el corporatismo no es un proceso unidireccional ni inevitable, pero denuncia su rechazo a reconocer tendencias meso y microcorporatistas que signifiquen una ruptura con el macrocorporatismo. Marques-Pereira ${ }^{1}$ (1999) analizó la taxonomía propuesta por Schmitter (1974), quien distingue el corporatismo societal como neocorporatismo, del corporatismo de Estado o corporatismo, para precisar que las ganancias de los intercambios políticos son disímiles en razón de las asimetrías de poder. En el primero, los partidos políticos compiten en las elecciones y gobiernan sobre la base de coaliciones, mientras que en el segundo el centralismo autoritario mono-ideológico controla el aparato burocrático y reprime otras demandas de representación política. 
La relevancia analítica del centralismo autoritario, que parecía haberse desvanecido con la caída del Muro de Berlín, recibe aliento cada vez con más frecuencia ante el ascenso y deseo de eternización en el poder de figuras autoritarias de derechas e izquierdas. Por su parte, el centralismo clientelista persevera como forma dominante de preservación de rancios políticos habituados al reparto milimétrico del aparato de Estado. El clientelismo se ha erigido como el mecanismo de cooptación más maleable y dúctil para garantizar la reproducción de los sistemas, dotado de la potencia para arrasar con cualquier intención de generalización de la meritocracia y capaz de reinventarse cotidianamente para sobreponerse a la vigilancia y control, cuya degradación, como la de la justicia, obedece a su endogeneidad al sistema. En el caso de las organizaciones económicas complejas - los gremios-, tal endogeneidad se aquilata en coyunturas políticas acuciosas:

también ocurre que algunos gremios en la creencia de que una buena relación con el gobierno les permite influir en comportamientos favorables de éste, se tornan condescendientes con el gobierno, haciendo que los abuse y utilice para conseguir apoyos en circunstancias políticas difíciles, cosa mal vista y peor interpretada (Kattan, 2013).

La acción colectiva neocorporatista derivada de la complejidad de estas organizaciones es como un gobierno basado en la matriz insumo-producto, en el que los agentes económicos que hacen parte de los eslabonamientos hacia atrás y hacia delante en cierta rama de la actividad económica coordinan entre sí y con el Estado a fin de enfrentar la incertidumbre inmanente a la economía de mercado y, además, garantizar ganancias extraordinarias. Por su parte, el aparato de Estado encuentra en esa asociación una forma versátil de garantizar la reproducción del sistema. Esta interacción sitúa a las partes en una ambigüedad estratégica, si se le compara con la de otros órdenes como la interdependencia de la competencia en el mercado o la heteronomía absoluta de los regímenes centralistas-totalitarios. La influencia recíproca es la manera como se ejecutan los acuerdos, y la iteración de ella para realizar ajustes graduales es el mecanismo para evitar sacar ventajas extraordinarias de los acuerdos neocorporatistas, siendo las formas advertidas por Schmitter (1985) el "tratamiento conjunto" o el "partir la diferencia" (p. 70).

Los acuerdos neocorporatistas requieren de legitimación y, con tal propósito, se buscan contrarrestar tanto como sea posible la oposición y la resistencia de los afectados directamente con ellos, y limar las asperezas con otros poderes con capacidad de intervenirlos. Este es el principal desafío del neocorporatismo (Schmitter, 1985) y, por ello mismo, el comportamiento estratégico de los suscriptores es decisivo. La anticipación de las conductas opositoras, regulatorias y de control se logran por consenso entre las partes. Es apenas obvio que el voto de silencio acerca de lo acordado territorias 40 179 
sea la primera garantía para que tal ejercicio de anticipación sea fructífero. Entre los suscriptores debe prevalecer, a toda costa, el discurso del convencimiento de que ese acuerdo no contraría las instituciones formales y que se hace con fines socialmente deseados, que por otra vía no podrían alcanzarse. La cuestión, finalmente, es si el contenido de los acuerdos corporatistas, los fines perseguidos y los instrumentos utilizados son o no compatibles con las aspiraciones sociales en materia de libertad económica y libertad política.

La interacción activa entre el Estado y las organizaciones complejas es incesante $\mathrm{y}$, en no pocas ocasiones, conflictiva. Cuadros del sector privado ejerciendo cargos públicos de decisión y representantes del gobierno en juntas directivas de organizaciones gremiales, por ejemplo, revelan la interdependencia alcanzada para que unos y otros puedan funcionar. Pero pueden también ocurrir tensiones y simpatías coyunturales en las que las formas de interacción son pasivas en el sentido que no implican entrecruzamientos burocráticos. La eficacia de unas y otras en tanto logro de metas estatales y privadas puede ser la misma, pero no así los costos para unos y otros, y ellos se deben cuantificar en términos de las ganancias o pérdidas en la autonomía.

\section{La estrategia del sector líder, complejidad organizacional y neocorporatismo}

\section{territarias 40}

La idea de que las grandes decisiones económicas se toman en la esfera de la política y no de la economía era recalcada por Lauchlin Currie a cuanto estudiante de economía tomaba alguno de sus cursos. La estructura decisional del Estado entraba, de esta manera, en el centro del interés intelectual de uno de los teóricos del desarrollo más influyentes en Colombia, probablemente el más prolífico y recordado por su originalidad. Algunos de sus biógrafos alaban el humor con el que manifestaba "que en Colombia a la mano invisible le toca esperar a que llegue la noche, cuando el gobierno duerme, para poder actuar" (Montenegro, 2012, p. 82). En tal sentido, afirmó que: "para elevar la tasa de crecimiento económico de un país es importante disminuir los impedimentos que obstruyen el buen funcionamiento de las fuerzas del mercado, así como adoptar políticas exógenas que estimulen la demanda real" (Currie, 1993, p. 229). El nudo del argumento está en lo que para él era precisamente la urdimbre de la intervención económica estatal colombiana $\mathrm{y}$, de manera complementaria, la opacidad con la que los capitalistas la enfrentan.

A Currie se debe la denominada estrategia del sector líder que, como quedó consignada en el Plan Nacional de Desarrollo "Las Cuatro Estrategias" (DNP, 1972 ) perseguía "ir concentrando mayores recursos del desarrollo urbano, con énfasis en la vivienda, la cual será financiada en gran parte por medio de nuevos ahorros generados por el ingreso nacional" (p. 28). $\mathrm{Al}$ lado de la vivienda, las exportaciones, los incrementos en la productividad y las mejoras en la distribución permitirían el 
avance hacia el desarrollo. Currie (1993) definió la estrategia del sector líder de la economía como aquella orientada a "detener o controlar una recesión, o a elevar el nivel de crecimiento económico a través del desvío de fondos hacia sectores que hubiesen demostrado su capacidad de moverse independientemente de la tendencia general" (p. 227). La tendencia de la actividad económica podía ser impulsada hacia el crecimiento, al estimular la actividad de sectores de gran peso en la economía y que, simultáneamente, poseyeran un número de eslabonamientos internos cuyo crecimiento se incrementaría como resultado del estímulo al sector líder. Esta estrategia gozaba, además, de la simpatía de la población que padecía con las precariedades habitacionales y cuyas aspiraciones en materia de solución del déficit habitacional y de incremento de puestos de trabajo se veían reflejadas en ella.

En términos agregados, la matriz insumo-producto del 2007 permite predecir que un incremento de $\$ 100$ en la demanda de activos inmobiliarios ocasiona otro tanto de $\$ 115,07$, de los cuales $\$ 49,6$ son atribuibles a encadenamientos directos y $\$ 65,47$ a efectos indirectos. Los multiplicadores son relativamente modestos, si se les compara con otras ramas de la actividad económica: un incremento de $\$ 100$ produce un aumento en las remuneraciones de $\$ 0,00$, cuando en ciertas ramas industriales puede ser de $\$ 0,83$ y el incremento en el valor agregado es de $\$ 0,06$; mientras que en obras civiles alcanza $\$ 49,65$. Un incremento en la demanda de
$\$ 10$ millones ocasiona 0,03 empleos adicionales, mientras que con la misma suma, en ciertas ramas industriales, se producen 8,3 nuevos puestos de trabajo y en obras civiles 7,01 (Hernández, 2011). Por tanto, hoy por hoy la trascendencia de la vivienda como sector líder de la economía es relativamente baja desde la perspectiva de los efectos multiplicadores; pero, en cambio, los efectos indirectos del crecimiento de la demanda son considerables, y de allí el porqué de la existencia de una organización compleja que aglutine a los constructores con los productores de materiales de construcción e intermediarios financieros dedicados a la fiducia inmobiliaria y al negocio hipotecario.

La Cámara Colombiana de la Construcción (CAMACOL) es una organización gremial que se ha ido complejizando desde 1957 , año en el que una asamblea de constructores realizada en Medellín decidió su conformación, hasta la actualidad, cuando el gremio reporta contar con 21 afiliados y cerca de 1700 compañías vinculadas con la producción residencial, entre los que se cuentan, además de los constructores y promotores inmobiliarios, a contratistas y consultores, industriales, comerciantes, entidades financieras, fiduciarias y otras. El marco de su representación funcional se concreta en dos estrategias:

- "Actúa ante las diferentes ramas del poder público y organismos del Estado para coadyuvar en la construcción de políticas públicas y en procura de normas que estimulen el desarrollo de territorias 40

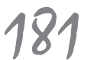




\section{territarias 40}

la industria de la construcción, el desarrollo urbano de las ciudades colombianas y el de los afiliados a la Cámara;

- Gestiona ante el Gobierno Nacional políticas para vivienda de bajo costo que tengan un carácter integral y abarquen aspectos como la tierra, urbanización, financiación, servicios, construcción, ventas y adjudicación" (CAMACOL, s.d.).

La demanda de activos residenciales en un contexto de urbanización persistente se amplía como resultado de los cambios demográficos que dan lugar al incremento en el número de hogares, así como por el interés de las personas solventes de contar con un activo que, además de preservar el poder adquisitivo de los ahorros, reditúe periódicamente una suma que juzgan superior al rendimiento real que obtendrían en el mercado financiero. Aunque el rendimiento real del alquiler a corto plazo (año a año) está revestido de una volatilidad considerable mediada en parte por el comportamiento de la inflación, el de mediano plazo (de cuatro años) es más estable, y revela, como en el caso de Bogotá, que han ocurrido varios ciclos pero que en el actual, iniciado hacia el 2002, la rentabilidad real ha alcanzado una diferencia con la rentabilidad de los depósitos a término fijo de hasta el 17\% real, siendo la más elevada la que experimentan los propietarios de los inmuebles habitados por los hogares menos solventes (Jaramillo \& Cuervo, 2014).

Desde la creación del Sistema Nacional de Vivienda de Interés Social en 1991, en Colombia y, especialmente en sus metrópolis, los productores de vivienda para los segmentos de población con ingresos precarios recibieron estímulos de diversa naturaleza, a fin de que con su intervención se acelerará la resolución del déficit cuantitativo de vivienda. La eficacia de tales estímulos, tal como ocurría con el sistema precedente de gestión estatal integral, estuvo limitada por la incapacidad estructural del Estado colombiano de producir suelo urbanizado para hogares pobres en condiciones de cantidad y localización requeridas para atender la demanda, así como la insolvencia crónica de la población potencialmente beneficiaria de los subsidios (Alfonso, 2007). Además del incentivo tributario consistente en la devolución del IVA de los materiales de construcción en los segmentos de la vivienda de interés social, el contexto económico para la producción de vivienda se transformó decididamente al final del siglo $\mathrm{XX}$, con incrementos anuales en los costos de construcción de $24,7 \%$ en 1990 a 10,1\% en 1999. A partir del año siguiente, el índice anual de costos de la vivienda se redujo a un dígito, lo que facilitó el cierre financiero de los proyectos de vivienda de interés social.

¿Cuál ha sido el resultado de la política de vivienda instaurada desde 1991? Las limitaciones para producir suelo edificable para la vivienda de hogares pobres no han sido superadas, no obstante que el aparato de Estado dedicado a la planificación urbana cuenta con una variedad de instrumentos para intervenir activamente sobre la economía del tipo casino que impera en los 
mercados del suelo urbano, en la que los propietarios optan por la valorización antes que por el rendimiento de la tierra. La producción residencial formal para hogares pobres se realiza generalmente en proximidad cuando no en los mismos lugares en donde tiene lugar la producción informal, quedando la competencia circunscrita a la mejor calidad material que proponen los constructores formales contra las áreas más amplias alcanzadas con el desarrollo progresivo que caracteriza a la informalidad urbana. Con las mismas deficiencias urbanísticas, los hogares pobres generalmente con más miembros que el promedio metropolitano, optan por el mercado que le ofrece las áreas más amplias.

\section{La política pública de vivienda y el acuerdo neocorporatista de los Macroproyectos de Interés Social Nacional}

Tres características distinguen a la vivienda de otros bienes: su inmovilidad, durabilidad y heterogeneidad (Tu, 2003). Si estos tres rasgos se vinculan con el elevado precio de mercado, es posible entender por qué la elección de producción/ localización residencial es una decisión irreversible (Abramo, 2011), la de localización/financiación la torna un activo propicio para la colocación financiera segura, esto es, hipoteca con garantía real (Alfonso, 2012) y, por último, por qué la localización/diferenciación hacen que ninguna unidad de vivienda sea igual a otra, es decir, es un mercado segmentado
(Tu, 2003; Alfonso y Amézquita, 2017). Las políticas de vivienda se han dirigido a superar las penurias habitacionales en los segmentos de mercado de hogares pobres, como también como política anti-cíclica al estimular la demanda en los segmentos para ingresos medios, generalmente con incentivos financieros asociados con el subsidio a la tasa de interés hipotecaria.

Las penurias habitacionales de una considerable porción de los hogares pobres son un fenómeno recurrente en las metrópolis latinoamericanas, sobre el que han girado buena parte de las políticas económicas y sociales, sin que los resultados obtenidos gocen del beneplácito general, ya por su insuficiencia cuantitativa y cualitativa o también por coadyuvar a la reproducción e intensificación de la segregación socio-espacial, uno de los rasgos distintivos de sus estructuras económicas y residenciales. El déficit cuantitativo se ha reducido al tiempo que el déficit cualitativo se ha incrementado, situación a la que Cohen y colaboradores (2016, p. 14) denominan como "casas sin gente y gente sin casas" en la que las políticas de estímulo a la producción habitacional priman sobre las políticas urbanas y, por ello, ocasionan déficits crecientes en servicios y equipamientos urbanos y, además, como en el caso de México (Ziccardi, 2016) y de Chile (Rodríguez y Rodríguez, 2016), inducen el deterioro ambiental y físico y el incremento considerable en la inseguridad.

Las condiciones económicas e institucionales para la producción y circulación de la vivienda en Colombia han atravesado territorias 40

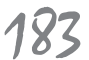


por varias etapas, en cuyo tránsito se han efectuado rupturas en las formas de gestión que han dado lugar a múltiples periodizaciones. Con la Ley 3 de 1991, por ejemplo, se eliminó la gestión estatal que integraba la promoción, la producción y la financiación de la vivienda y se cambió el aparato estatal de soporte por uno mucho más pequeño encargado de la administración del subsidio y en parte de la promoción. De manera complementaria, la introducción del sistema multibanca implicó la liquidación del sistema financiero especializado en la vivienda, fenómeno acentuado con posterioridad a la crisis del sistema UPAC que había operado sin sobresaltos desde su instauración en 1972, cuya crisis se agudizó en la coyuntura 1998-1999 y fue inducida por el cambio unilateral de las reglas de indexación que desencadenó la entrega de alrededor de 60000 viviendas a los bancos en dación en pago por los saldos insolutos de los créditos hipotecarios, con episodios críticos para la regulación financiera del Estado, como el ocurrido entre noviembre de 1990 y junio de 1992 cuando el ajuste mensual a la UPAC superó el límite de la usura (figura 1).

Una periodización desde la perspectiva de los cambios en los costos de la construcción residencial resulta útil, en la medida en que facilita la comprensión de

Figura 1. Variaciones nominales mensuales de la Unidad de Poder Adquisitivo Constante (UPAC), la inflación y el límite administrativo a las tasas de interés (usura), Colombia 1974-1993

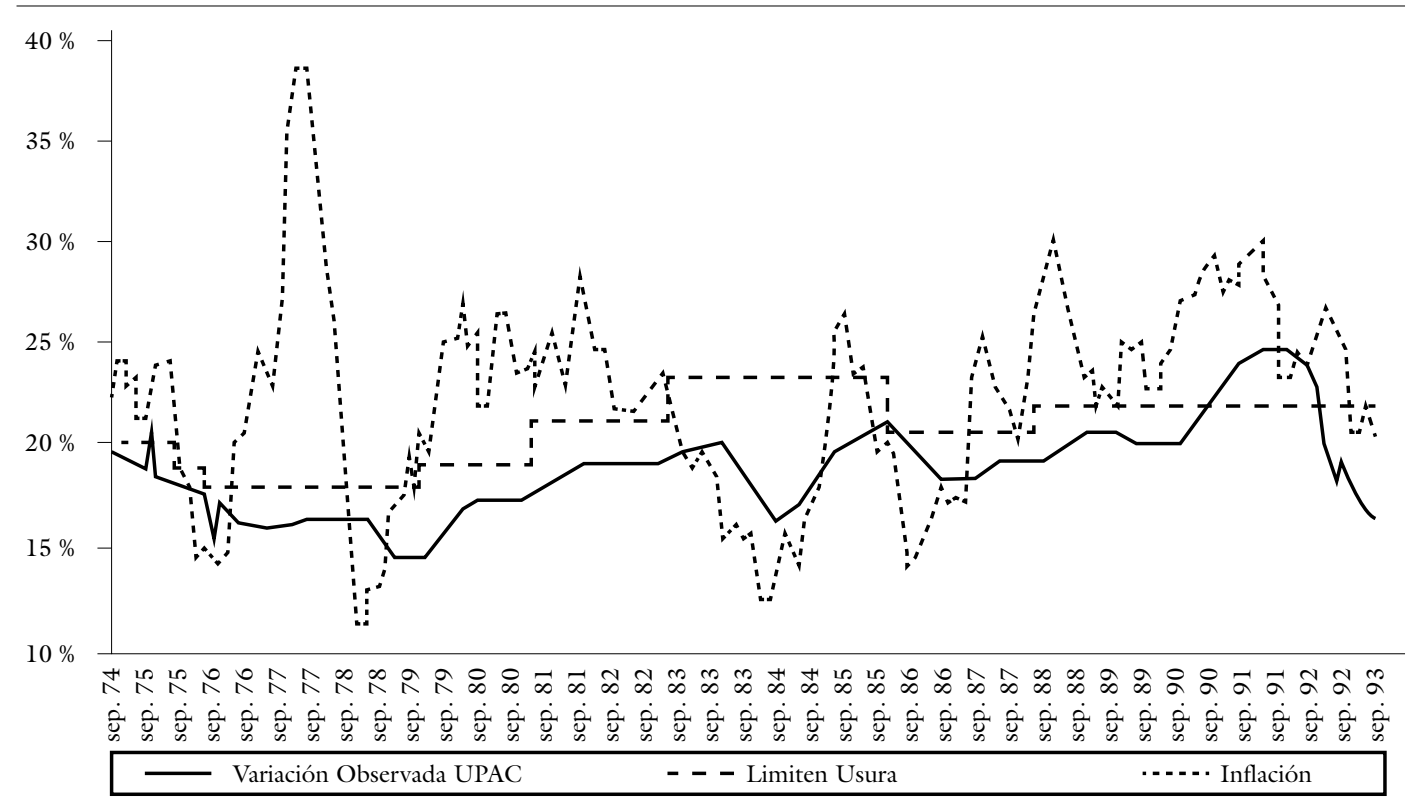


los acuerdos neocorporatistas vinculados con el comportamiento de la economía. El primer periodo se inicia con la inflación galopante de comienzos de los años setenta, contexto en el que se introduce el sistema de valor constante - UPAC- por medio del que se buscó la preservación del poder adquisitivo de los ahorros y el valor de las deudas hipotecarias. Posteriormente, el control de la inflación se afianzó como fin primordial de la política económica desde la transición al siglo XXI, con lo que se procuró evitar la reedición de episodios inflacionarios como el de 1977 en el que a mitad de año ya se había alcanzado el $27,2 \%$, lo que significó un acumulado del año completo del $41,7 \%$, espiral de precios que motivó un paro nacional que concluyó luego de una veintena de muertos, disturbios en las metrópolis colombianas y con la conquista laboral de la negociación del salario mínimo legal que, si bien existía desde la década anterior, no se le otorgaba mayor importancia. Este periodo finalizó con el logro del propósito de llevar la inflación a un dígito, que fue alcanzado en mayo de 1999 y, a partir de entonces, no ha habido mayores sobresaltos e inclusive han ocurrido esporádicos episodios deflacionarios.

La gestión estatal integrada de la vivienda enfrentó el problema de los elevados ajustes de los costos de construcción, tal como ocurrió en la coyuntura inflacionaria de 1977-1978, cuando el índice de costos de la construcción osciló alrededor del $30,0 \%$ anual. A lo largo de este periodo, la estacionalidad de los ajustes es muy clara; pues, justo desde 1978, cuando se conocen los primeros resultados de la negociación del ajuste al salario mínimo legal pos-paro nacional, la variación en el índice de costos de la construcción del mes de enero fue, casi invariablemente, la más elevada del año (figura 2). Este fenómeno fue cediendo durante los primeros años de la política del subsidio a la demanda, hasta que la política anti-inflacionaria alcanzó su meta de ajuste a un dígito hacia mediados de 1999, momento en el que se agudiza la crisis hipotecaria. El acuerdo que introduce el esquema multibanca es el resultado de un balance relativamente simple pues, en efecto, la banca especializada en vivienda realizaba su intermediación sobre la base de una tasa de interés indexada con base en la inflación que, por razones de la política económica, era inferior a las tasas de interés del resto del sistema, especialmente de las de los depósitos a término fijo. El manejo de sistemas con tasas estructuralmente diferentes se juzga inconveniente para la economía y se introduce el sistema multibanca. El cambio de las reglas de indexación, de la inflación a la tasa de los depósitos a término fijo, elevó considerablemente los costos de los créditos hipotecarios para los acreedores del sistema, cuyos salarios se ajustan con la inflación y allí sobrevino la crisis hipotecaria.

El segundo periodo comienza en julio de 1999. El coletazo de la crisis fue una contracción del ICCV de $-0,92 \%$ en junio de 1998, fenómeno inédito en Colombia hasta entonces. El segundo periodo comienza precisamente con la recuperación territarias 40

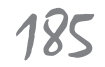


del ICCV, pero en un nuevo contexto económico: el de la reducción de la inflación a un dígito. En 1999 el Índice de Costos de la Construcción de Vivienda (ICCV) alcanzó el 10,1\% e, iniciado el siglo XXI, prosiguió su tendencia decreciente al ajustarse en $9,6 \%$ en el 2000 , la que persistirá hasta finales del 2009 cuando se acumularon considerables contracciones más persistentes que las experimentadas una década atrás. La estacionalidad continuó, aunque en algunos años los mayores ajustes ocurrieron en febrero.

En septiembre de 2008, la cuarta banca de inversión de los Estados Unidos, Lehman Brothers, declaró su bancarrota $y$, ante la negativa de otros bancos a comprarla, se desata una crisis financiera sin precedentes que da lugar a la recesión mundial. Según la Reserva Federal de los Estados Unidos, una docena de entidades financieras entraron en riesgo de quiebra en un lapso de dos semanas, y la solvencia del conjunto del sistema entró en duda, fenómeno que afectó al sector real por medio de la contracción de los fondos requeridos para la operación de firmas de todo tamaño. Las "hipotecas subprime" fue el derivado financiero que dio lugar a la crisis a la que sobrevino la llamada "burbuja inmobiliaria", caracterizada por la caída de los precios de mercado de los activos inmobiliarios artificialmente elevados como parte de la estrategia de valorización que en adelante se conocerá como la financiarización. La reducción de las tasas de interés de la FED, el incremento en la liquidez del sistema y el empleo de instrumentos fiscales para el rescate de las entidades financieras, conformaron un paquete de intervención que, sin embargo, no logró contener el desborde de los efectos de la recesión de los Estados Unidos en la economía mundial.

Ese desborde de la crisis fue inmediato en la economía mundial. En Colombia las previsiones del crecimiento comenzaron a ser revaluadas y el crecimiento negativo del Producto Interno Bruto (PIB) del cuarto trimestre 2008 confirmó la entrada de la economía colombiana en el club de los países en recesión. El ICCV comenzó a experimentar crecimientos negativos que se extendieron hasta el final de 2008, mientras que en enero y febrero del 2009 su cambio fue positivo, lo que no era sintomático de la recuperación de la cadena sino, como se sabía, resultado de la estacionalidad que impera en los ajustes de rentas de la economía al inicio de cada año; de hecho, el crecimiento negativo del ICCV se prolongó de marzo a diciembre del 2009 (figura 2).

Era evidente la necesidad de realizar intervenciones activas a fin de contrarrestar los efectos del ciclo recesivo. La administración Uribe II se había propuesto una meta para el segundo cuatrienio de 828433 soluciones para el financiamiento de la vivienda de interés social en el marco de la estrategia Ciudades Amables y el instrumento de los Macroproyectos de Interés Social Nacional enunciado en los artículos 79 y 82 de la Ley 1151 de 2007. El 2 de noviembre del mismo año se promulgó el Decreto reglamentario 4260 que en su artículo primero establece que: 


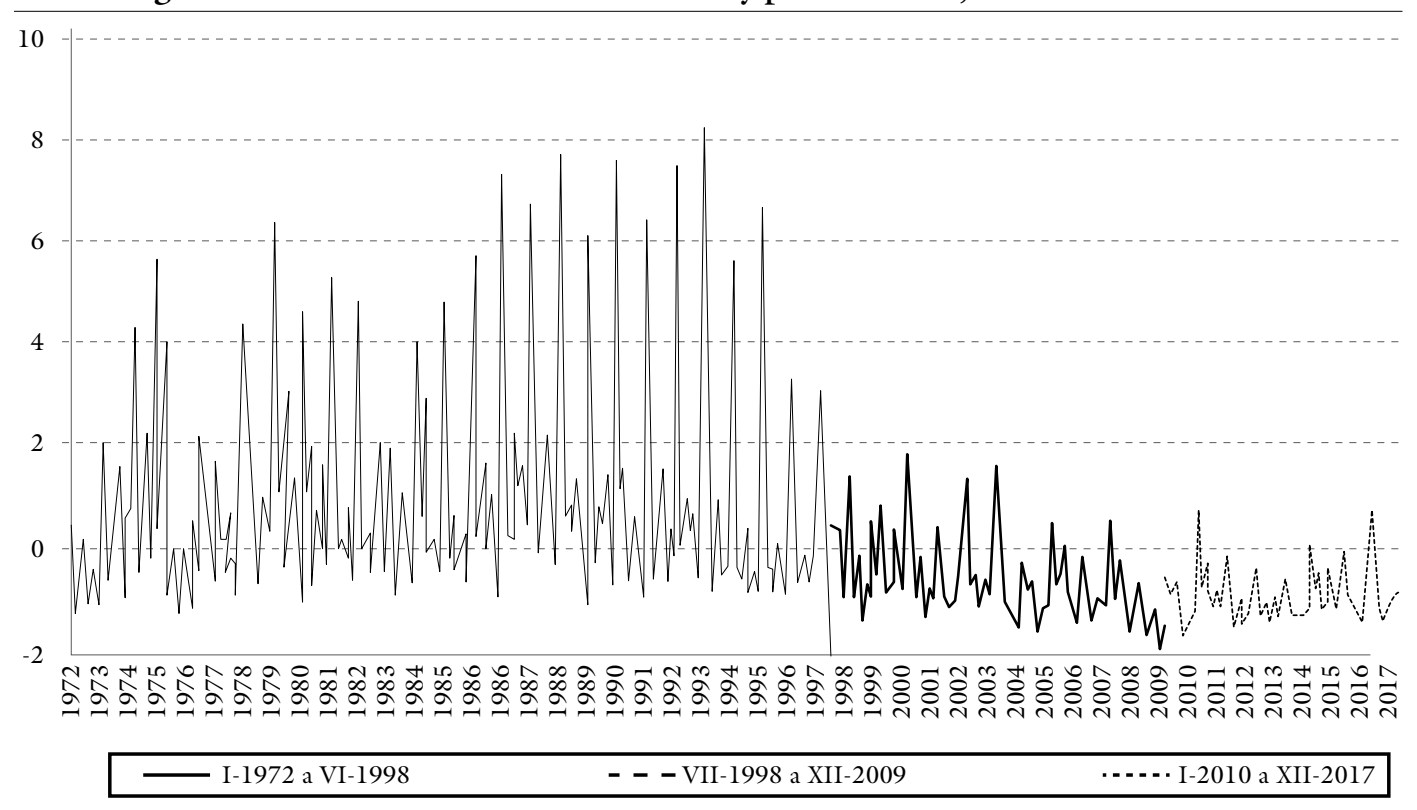

Fuente: elaboración propia con base en el ICCV del DANE.

Los Macroproyectos de Interés Social Nacional son el conjunto de decisiones administrativas y actuaciones urbanísticas adoptadas por el Gobierno Nacional, en lo que se vinculan instrumentos de planeación, financiación y gestión del suelo para ejecutar una operación de gran escala que contribuya al desarrollo territorial de determinados municipios, distritos, áreas metropolitanas o regiones del país.

Los Macroproyectos de que trata el presente Decreto se refieren a la ejecución de operaciones urbanísticas integrales de gestión y provisión de suelo para vivienda, con especial énfasis en vivienda de interés social y vivienda de interés prioritario.
El Macroproyecto deberá proveer suelo para desarrollar un número de viviendas de interés social que no podrá ser inferior al $(1 \%)$ del número de hogares existentes en los municipios o distritos objeto del macroproyecto, de conformidad con las estadísticas del DANE.

Parágrafo 1. Las decisiones administrativas y actuaciones urbanísticas adoptadas por el Gobierno Nacional conforman la acción urbanística de la Nación.

Parágrafo 2. Siempre que en este Decreto se mencionen los Macroproyectos se entenderá que se hace referencia a los Macroproyectos de Interés Social Nacional de que trata el Artículo 79 de la Ley 1151 de 2007. territarias 40 
A la luz de la discusión teórica se analizan a continuación tres rasgos del acuerdo neocoporatista MISN: la legitimidad, la complejidad y el status del privado y el tratamiento conjunto.

Legitimidad. En el Artículo $3^{\circ}$ el Decreto reproduce el argumento del Artículo 79 de la Ley 1151 en el sentido que los MISN constituyen una norma de superior jerarquía en el ordenamiento territorial, decisión amparada en lo dispuesto en la materia por el Artículo $10^{\circ}$ de la Ley 388 de 1997; sin embargo, el contenido de los cuatro numerales de esta regla no es afín con los MISN. Por tanto, se configuró una transgresión a la autonomía municipal en el ordenamiento territorial consagrada en el numeral 2 del Artículo $1^{\circ}$ de la Ley 388 de 1997, cuyos efectos prácticos consisten en eliminar la concertación ex ante con los municipios, derivada de la aplicación de los principios de coordinación y concurrencia, en particular en los MISN de iniciativa privada. El Artículo 11 del Decreto 4260 formalizó la transgresión de estos principios en la etapa de formulación de los MISN, pues es mediante comunicación del Ministerio de Ambiente, Vivienda y Desarrollo Territorial que los municipios concernidos podrán manifestarse ex post a la decisión ya tomada. Resuelto el impasse de la autonomía territorial para los MISN, el gobierno nacional decidió sobre la modificación del perímetro urbano municipal y las áreas de expansión - parágrafo $1^{\circ} \mathrm{del}$ Artículo 12-, así como sobre las licencias urbanísticas a ser expedidas con sujeción al MISN y no a las normas de ordenamiento territorial municipal vigentes - Artículo 13-.

Pasaron 14 meses de la promulgación del Decreto 4260 hasta la adopción de los primeros MISN y 21 hasta que la Corte Constitucional admitió las demandas de inconstitucionalidad. El 18 de diciembre de 2008 fue un día de inusitada actividad regulatoria en el Ministerio de Ambiente, Vivienda y Desarrollo Territorial, día en el que el ministro firmó las resoluciones por medio de las que se adoptaron cuatro MISN (tabla 1), cuando la crisis recesiva comenzaba su cuarto mes sin indicios de recuperación.

Complejidad y status. En la admisión de la demanda de inconstitucionalidad, el magistrado ponente sintetizó la precariedad del modelo territorial de Estado en relación con los MISN, al conceder a los demandantes que "no se corresponde con la autonomía y los principios que orientan el proceder administrativo de las entidades territoriales" (Corte Constitucional, Sentencia C-149 de 2010). El abogado del gobierno nacional, quien desde marzo de 2012 comenzaría su ejercicio como Fiscal General de la Nación, basó su argumento en supuestas deficiencias argumentativas de los demandantes. El abogado de CAMACOL, exconstituyente y posteriormente jefe del equipo negociador de la paz y precandidato a la presidencia de la república, basó su argumento de exequibilidad en que la coexistencia, para un mismo ámbito de aplicación, de los instrumentos de planificación de la Ley 388 de 1997 y de la norma imputada a los que conside- 
ró como de "gestión excepcional” y, de manera complementaria, que tal norma se ajustaba al principio de subsidiariedad en vista de que los municipios persiste el déficit habitacional. El Ministerio de Hacienda y Crédito Público argumentó que con los MISN el gobierno de la administración Uribe pretendía la realización de "los fines del Estado", mientras que el Departamento Nacional de Planeación los vinculó a la garantía del Estado a los derechos fundamentales. La Procuraduría General de la Nación llegó a la conclusión de que los MISN antes que vaciar las competencias municipales y limitar su autonomía la reafirma, mientras que entre los argumentos de los académicos sobresale el que se adhiere al modelo centralista al argumentar la superioridad de la república unitaria frente a la autonomía local.

Tratamiento conjunto. En el análisis de los cargos, la Corte estableció que:

la Ley del Plan Nacional de Desarrollo no puede alterar el sistema de fuentes estableciendo una supremacía entre los MISN y los POTS; permitirlo conduciría a alterar el marco constitucional que regula las relaciones entre la Nación y las entidades territoriales (Corte Constitucional, numeral 6.6 Sentencia C-149 de 2010).

Y sentenció la inexequibilidad de la norma en términos de su validez jurídica que, en términos prácticos, significó que:

la sentencia tiene efectos hacia el futuro, es decir, a partir del día cinco (5) de marzo de
2010, con lo cual no se produce traumatismo alguno. Las consecuencias de la inexequibilidad se aplicarán para nuevos megaproyectos y no para los que se encuentran en curso (Corte Constitucional, numeral 6.6 Sentencia C-149 de 2010).

El traumatismo potencial consistía en que alguno o los diez MISN adoptados por el Ministerio, tres de ellos de iniciativa privada, (tabla 1) tuviera que suspenderse si la sentencia de inexequibilidad se hubiese proferido en términos de su eficacia jurídica.

Los efectos duraderos del acuerdo neocorporatista MISN no pueden apreciarse sin sus efectos urbanísticos y políticos. Seis meses antes de proferida la Sentencia C-149, el gobierno había modificado el Decreto 4260, por medio del Decreto 3671 del 25 de septiembre del 2009 en el que, además de pautas de procedimiento, decidió que los MISN se realizarían en cualquier tipo de suelo y que las licencias se expedirían con arreglo a lo estipulado en el MISN y no en el POT municipal. En el régimen de transición determinó que aquellos MISN que se encontrarán en trámite para su adopción se sujetarían a las nuevas disposiciones. El periodo recesivo culminó hacia finales del 2009, hecho que, sumado a la decisión de la Corte Constitucional, llenó de beneplácito a los constructores y partícipes de la cadena que exaltaron la labor del gremio. Los ministros de vivienda, entrante y saliente, celebraron que el arreglo hubiese surtido efectos sin "traumatismo alguno". territarias 40

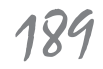


Tabla 1. Los MISN de primera y segunda generación: adopción y financiación al finalizar el 2017

\begin{tabular}{|c|c|c|c|c|c|c|}
\hline \multirow{2}{*}{ Ciudad } & \multirow{2}{*}{ Nombre del MISN } & \multirow{2}{*}{ Gestores } & \multicolumn{2}{|c|}{ Fechas de las resoluciones } & \multicolumn{2}{|c|}{$\begin{array}{l}\text { Aportes nacionales } \\
\text { (millones de pesos) }\end{array}$} \\
\hline & & & Adopción & Modificación & misn & $\begin{array}{l}\text { Otras } \\
\text { fuentes }\end{array}$ \\
\hline \multicolumn{7}{|c|}{ Primera generación } \\
\hline Barranquilla & Villas de San Pablo & $\begin{array}{l}\text { Fundación Mario } \\
\text { Santodomingo }\end{array}$ & $18 / 12 / 2008$ & $13 / 06 / 2012$ & 20000 & 54168 \\
\hline Cartagena & $\begin{array}{l}\text { Ciudad del } \\
\text { Bicentenario }\end{array}$ & $\begin{array}{l}\text { Fundación Mario } \\
\text { Santodomingo }\end{array}$ & $18 / 12 / 2008$ & $17 / 12 / 2009$ & 29000 & 70876 \\
\hline Medellín & Nuevo Occidente & Alcaldía & $18 / 12 / 2008$ & $17 / 12 / 2009$ & 86543 & 33199 \\
\hline Neiva & $\begin{array}{l}\text { Bosques de San } \\
\text { Luís }\end{array}$ & $\begin{array}{l}\text { Alcaldía y } \\
\text { Gobernación }\end{array}$ & $18 / 12 / 2008$ & $17 / 12 / 2009$ & 35932 & 10000 \\
\hline Manizales & San José & Alcaldía & $27 / 07 / 2009$ & $06 / 08 / 2010$ & 40000 & \\
\hline Soacha & Ciudad Verde & Amarilo S. A. & $03 / 09 / 2009$ & $27 / 07 / 2010$ & & 13758 \\
\hline Pereira & $\begin{array}{l}\text { Ciudadela Gonzalo } \\
\text { Restrepo Vallejo }\end{array}$ & Alcaldía & $04 / 11 / 2009$ & $14 / 07 / 2010$ & 10000 & 34519 \\
\hline Buenaventura & $\begin{array}{l}\text { Ciudadelas San } \\
\text { Antonio y Nueva } \\
\text { Buenaventura }\end{array}$ & Fonvivienda-Alcaldía & $09 / 02 / 2009$ & $27 / 12 / 2012$ & 99852 & 4622 \\
\hline Cali & $\begin{array}{l}\text { Altos de Santa } \\
\text { Elena }\end{array}$ & Fonvivienda-Alcaldía & $14 / 12 / 2009$ & & 33700 & 2361 \\
\hline Cali & Ecociudad Navarro & Fonvivienda-Alcaldía & $23 / 12 / 2009$ & $06 / 08 / 2010$ & 1055 & \\
\hline \multicolumn{7}{|c|}{ Segunda generación } \\
\hline Palmira & La Italia & Jaramillo Mora S. A. & $07 / 02 / 2012$ & & & 22173 \\
\hline Tuluá* & Ciudadela del Valle & Grupo ODINSA S. A. & $03 / 08 / 2012$ & & & \\
\hline Candelaria & $\begin{array}{l}\text { PIDU Mirador del } \\
\text { Frayle }\end{array}$ & IC Prefabricados S. A. & $27 / 06 / 2014$ & & & \\
\hline Piedecuesta & Pienta & Gobernación & $21 / 11 / 2014$ & $12 / 07 / 2016$ & & \\
\hline Cali & Santa Fe & $\begin{array}{l}\text { Constructora Bolívar } \\
\text { S. A. }\end{array}$ & $23 / 08 / 2017$ & & & \\
\hline
\end{tabular}

\section{territarios 40}

Fuente: Ministerio de Vivienda, Ciudad y Territorio.

(*) Proyecto al que se le declaró la pérdida de ejecutoriedad. 
Los tres MISN de iniciativa privada aportan el 72,6\% de las soluciones de vivienda del conjunto de los de primera generación y se distinguen de los de iniciativa pública por producir una densidad bruta de ocupación excepcionalmente elevada (tabla 2). Los resultados en términos de eficacia, esto es, de ocupación de las so- luciones ofrecidas es bastante heterogéneo, pues en ningún caso, y luego de una década de adopción, se ha alcanzado el $100 \%$ de ocupación, lo que confirma que en Colombia, al igual que en México y en Chile, también ocurre el fenómeno de "casas sin gente y gente sin casas", contrario a la conclusión que llegan los estudios

Tabla 2. Los MISN de primera y segunda generación: soluciones de vivienda e indicadores de resultado al finalizar el 2017

\begin{tabular}{|c|c|c|c|c|c|c|c|c|}
\hline \multirow[b]{2}{*}{ Ciudad } & \multirow[b]{2}{*}{ Nombre del MISN } & \multirow[b]{2}{*}{ Gestores } & \multirow{2}{*}{$\begin{array}{c}\text { Área } \\
\text { bruta } \\
\text { (ha) }\end{array}$} & \multicolumn{3}{|c|}{ Soluciones de vivienda } & \multicolumn{2}{|c|}{$\begin{array}{l}\text { Indicadores de } \\
\text { resultado }\end{array}$} \\
\hline & & & & $\begin{array}{c}\text { Proyec- } \\
\text { tadas }\end{array}$ & $\begin{array}{l}\text { Entre- } \\
\text { gadas }\end{array}$ & $\begin{array}{l}\text { Subsidios } \\
\text { asignados }\end{array}$ & $\begin{array}{c}\text { Avance } \\
(\%)\end{array}$ & $\begin{array}{c}\text { Densidad } \\
\text { bruta } \\
\text { (vIV/ha) }\end{array}$ \\
\hline \multicolumn{9}{|c|}{ Primera generación } \\
\hline Barranquilla & $\begin{array}{l}\text { Villas de San } \\
\text { Pablo }\end{array}$ & $\begin{array}{l}\text { Fundación Mario } \\
\text { Santodomingo }\end{array}$ & 133,3 & 18871 & 1949 & 893 & 10,3 & 141,6 \\
\hline Cartagena & $\begin{array}{l}\text { Ciudad del } \\
\text { Bicentenario }\end{array}$ & $\begin{array}{l}\text { Fundación Mario } \\
\text { Santodomingo }\end{array}$ & 388,0 & 65138 & 3695 & 1284 & 5,7 & 167,9 \\
\hline Medellín & Nuevo Occidente & Alcaldía & 125,9 & 11455 & 9424 & 3624 & 82,3 & 91,0 \\
\hline Neiva & $\begin{array}{l}\text { Bosques de San } \\
\text { Luís }\end{array}$ & $\begin{array}{l}\text { Alcaldía y } \\
\text { Gobernación }\end{array}$ & 36,7 & 3928 & 2447 & 2519 & 62,3 & 106,9 \\
\hline Manizales & San José & Alcaldía & 98,7 & 5974 & 24 & 129 & 0,4 & 60,5 \\
\hline Soacha & Ciudad Verde & Amarilo S.A. & 328,0 & 49656 & 32374 & & 65,2 & 151,4 \\
\hline Pereira & $\begin{array}{l}\text { Ciudadela } \\
\text { Gonzalo } \\
\text { Restrepo Vallejo }\end{array}$ & Alcaldía & 163,3 & 13971 & 3335 & 550 & 23,9 & 85,5 \\
\hline Buenaventura & $\begin{array}{l}\text { Ciudadelas San } \\
\text { Antonio y Nueva } \\
\text { Buenaventura }\end{array}$ & $\begin{array}{l}\text { Fonvivienda- } \\
\text { Alcaldía }\end{array}$ & 215,3 & 4052 & 1290 & 1289 & 31,8 & 18,8 \\
\hline Cali & $\begin{array}{l}\text { Altos de Santa } \\
\text { Elena }\end{array}$ & $\begin{array}{l}\text { Fonvivienda- } \\
\text { Alcaldía }\end{array}$ & 46,6 & 5000 & 2136 & 1514 & 42,7 & 107,2 \\
\hline Cali & $\begin{array}{l}\text { Ecociudad } \\
\text { Navarro }\end{array}$ & $\begin{array}{l}\text { Fonvivienda- } \\
\text { Alcaldía }\end{array}$ & 67,3 & 6000 & & & - & 89,2 \\
\hline
\end{tabular}




\begin{tabular}{|c|c|c|c|c|c|c|c|c|}
\hline \multirow[b]{2}{*}{ Ciudad } & \multirow[b]{2}{*}{ Nombre del MISN } & \multirow[b]{2}{*}{ Gestores } & \multirow{2}{*}{$\begin{array}{c}\text { Área } \\
\text { bruta } \\
\text { (ha) }\end{array}$} & \multicolumn{3}{|c|}{ Soluciones de vivienda } & \multicolumn{2}{|c|}{$\begin{array}{l}\text { Indicadores de } \\
\text { resultado }\end{array}$} \\
\hline & & & & $\begin{array}{c}\text { Proyec- } \\
\text { tadas }\end{array}$ & $\begin{array}{l}\text { Entre- } \\
\text { gadas }\end{array}$ & $\begin{array}{l}\text { Subsidios } \\
\text { asignados }\end{array}$ & $\begin{array}{c}\text { Avance } \\
(\%)\end{array}$ & $\begin{array}{c}\text { Densidad } \\
\text { bruta } \\
\text { (vIV/ha) }\end{array}$ \\
\hline \multicolumn{9}{|c|}{ Segunda generación } \\
\hline Palmira & La Italia & $\begin{array}{l}\text { Jaramillo Mora } \\
\text { S.A. }\end{array}$ & 97,1 & 6026 & 3825 & & 63,5 & 62,1 \\
\hline Tuluá* & $\begin{array}{l}\text { Ciudadela del } \\
\text { Valle }\end{array}$ & $\begin{array}{l}\text { Grupo ODINSA } \\
\text { S. A. }\end{array}$ & 31,0 & 3920 & & & - & 126,5 \\
\hline Candelaria & $\begin{array}{l}\text { PIDU Mirador } \\
\text { del Frayle }\end{array}$ & $\begin{array}{l}\text { IC Prefabricados } \\
\text { S.A. }\end{array}$ & 100,2 & 6568 & & 300 & - & 65,5 \\
\hline Piedecuesta & Pienta & Gobernación & 125,0 & 17226 & & & - & 137,8 \\
\hline Cali & Santa Fe & $\begin{array}{l}\text { Constructora } \\
\text { Bolívar S.A. }\end{array}$ & 164,4 & 18000 & & & - & 109,5 \\
\hline
\end{tabular}

Fuente: Ministerio de Vivienda, Ciudad y Territorio.

(*) Proyecto al que se le declaró la pérdida de ejecutoriedad.

del New School (Cohen, et al., 2016; Torres, 2016). A excepción del MISN localizado en Palmira, dentro de los denominados por el gobierno como de segunda generación por su adopción con posterioridad a la Sentencia C-149, los resultados son modestos; de hecho, al de Tulúa el gobierno nacional le declaró la pérdida de ejecutoriedad por no haberse surtido actuación alguna de parte del gestor luego de cinco años de su adopción.

En el seguimiento de académicos a los MISN se han acumulado un conjunto de elementos de análisis que valorizan los argumentos de los demandantes ante la Corte. En los casos de los MISN realizados en zonas de renovación de Manizales y Buenaventura, Acebedo (2016) ha denunciado que el traslado de la población beneficiaria se ha realizado bajo amenazas de expropiación de los terrenos que previamente ocupaban y se han vulnerado los mecanismos de participación de las comunidades, especialmente las consultas previas. En Ciudad Verde, del que participan, además de Amarilo, reconocidos productores inmobiliarios afiliados a CAMACOL como Urbansa, Constructora Bolívar, Coninsa, Marval, Prodesa y Ospinas, la mayor proporción de los residentes (el $55 \%$ ) provinieron de localidades pobres de Bogotá y el $98 \%$ recibió su vivienda en obra negra (Rubiano, 2017). El colapso de la movilidad cotidiana entre Bogotá y el municipio de Soacha se acentuó y continúa haciéndolo, a medida que se sigue ocupando Ciudad Verde; 
pues, en efecto, la capacidad de carga de Transmilenio y de los demás modos ha sido rebasada por la demanda, y que las demás vías que reforzarían el urbanismo existente no se construirán.

El tercer periodo inicia en enero de 2010, cuando hubo síntomas de superación de la recesión. La estacionalidad del ajuste de los costos de los materiales de construcción continuó, aunque a valores inferiores a los de los periodos precedentes. En medio de la recuperación del ICCV (figura 2), la Corte Constitucional profirió la Sentencia C-149 en los términos ya analizados. No obstante, esos síntomas se alteraron desde agosto de 2010 , cuando los indicadores trimestrales se volvieron a deteriorar y el ICCV a decrecer, y la prolongación de la crisis llegó hasta diciembre. En junio de 2012, la política de vivienda para hogares pobres experimentó un cambio sin precedentes, por cuanto con el Artículo 12 de la Ley 1537 se estableció que la vivienda se entregará a título Subsidio Familiar de Vivienda en Especie (SFVE) y que su gestión se realiza con base en la conformación de patrimonios autónomos en fiducias, siendo la meta de la administración Santos la entrega de 100000 sFve. Por su parte, los beneficiarios serán aquellos que estuviesen en condición de pobreza extrema, haber sido desplazados de manera forzada por los violentos, ser damnificados de desastres naturales u otra calamidad pública y estar habitando zonas de riesgo no mitigable, grupo dentro del que se priorizarían a los jefes de hogar, discapacitados y adultos mayores.
Algunas etapas de los MISN Villas de San Pablo, Ciudad del Bicentenario, Nuevo Occidente, Ciudadela Gonzalo Restrepo Vallejo y PIDU Mirador del Frayle se vienen desarrollando con el apalancamiento del SFVE. En enero de 2013 el gobierno estableció el mecanismo de baloteras para asignar al azar la vivienda gratuita en los casos en los que el número de postulantes supere el número de soluciones ofrecidas. El número de SFVE equivale al 51,7\% de las soluciones proyectadas en los MISN y la escala promedio de los proyectos está asociada positivamente con la jerarquía de las ciudades (tabla 3 ) y, aunque hay proyectos de cierta envergadura como los de Ciudad Equidad en Santa Marta y la Urbanización

Tabla 3. SFVE y municipios beneficiarios del programa de vivienda gratuita al finalizar el 2017

\begin{tabular}{|l|c|c|c|}
\hline & $\begin{array}{c}\text { Número } \\
\text { de sFve }\end{array}$ & $\begin{array}{c}\text { Número de } \\
\text { Municipios }\end{array}$ & $\begin{array}{c}\text { Tamaño } \\
\text { promedio }\end{array}$ \\
\hline $\begin{array}{l}\text { Zonas } \\
\text { Metropolitanas }\end{array}$ & 39389 & 30 & 1313 \\
\hline $\begin{array}{l}\text { Núcleos } \\
\text { metropolitanos }\end{array}$ & 28722 & 9 & 3191 \\
\hline $\begin{array}{l}\text { Municipios } \\
\text { metropolizados }\end{array}$ & 10667 & 21 & 508 \\
\hline Resto del país & 55767 & 183 & 305 \\
\hline Crecimiento robusto & 44393 & 122 & 364 \\
\hline Urbano endeble & 7336 & 28 & 262 \\
\hline Rural endeble & 3958 & 32 & 124 \\
\hline Frágil & 80 & 1 & 80 \\
\hline Total & 95156 & 213 & 447 \\
\hline
\end{tabular}

Fuente: elaboración propia con base en registros del Ministerio de Vivienda y Territorio al 31/12/2017. territarias 40

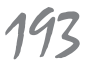


Las Gardenias, cada una con 4000 sFVE, la gran mayoría son de mediana y pequeña talla: en Bogotá y Medellín, las metrópolis colombianas, por ejemplo, se realizaron 22 proyectos de diferente tamaño, estrategia constructiva yuxtapuesta a los MISN.
La distribución espacial de los SFVE tiene un rasgo positivo, que es el de desconcentrar la producción residencial para hogares pobres; pues, el 58,6\% se localiza en zonas diferentes a las metropolitanas (tabla 3 , figura 3 ), con particular intensidad en

Figura 3. Grupos de municipios por número de beneficiarios del programa de vivienda gratuita al finalizar el 2017
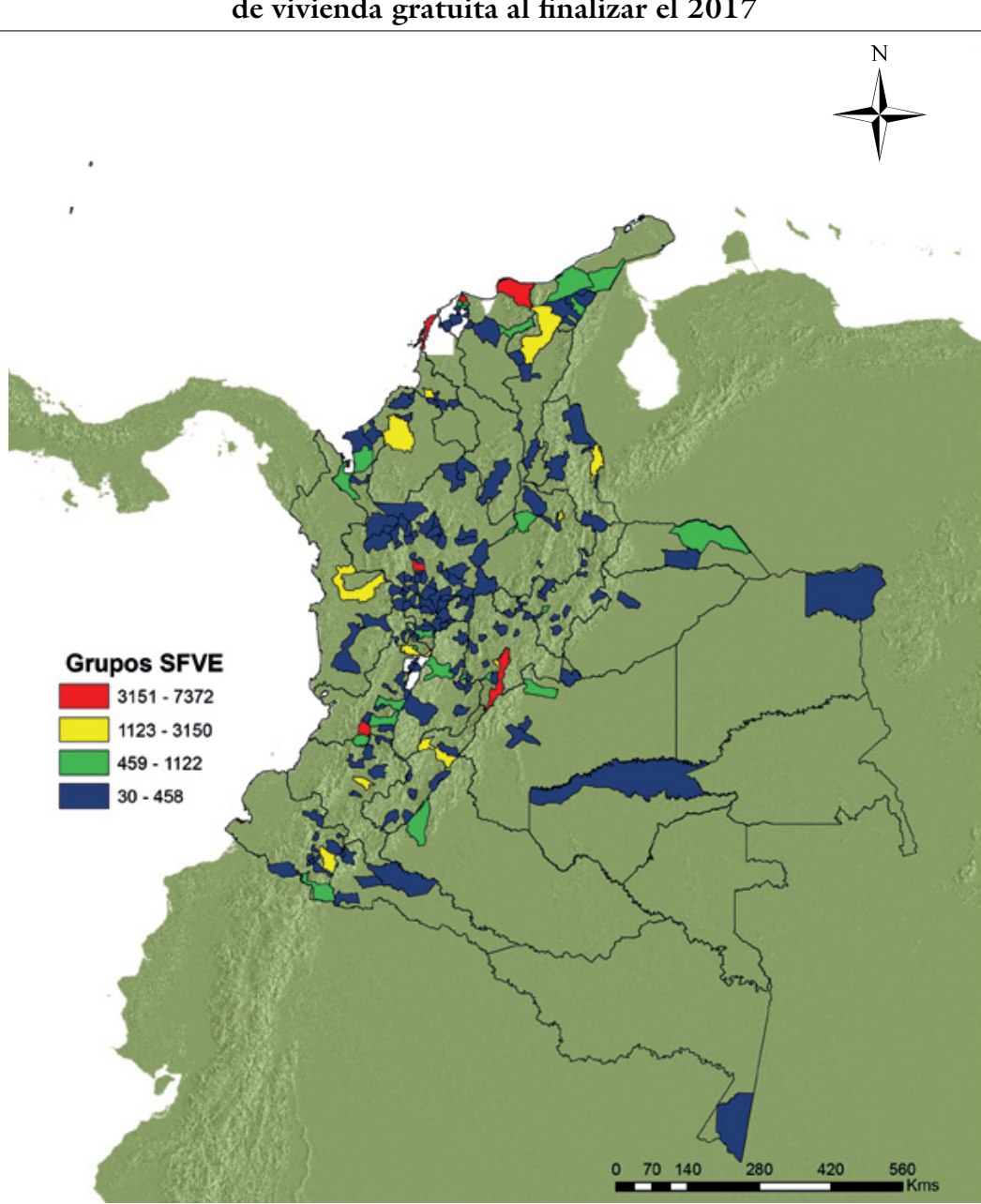
122 municipios con crecimiento poblacional robusto, en donde el déficit total es considerable. Al interior de las zonas metropolitanas es notable el caso de la de Bogotá, pues solamente dos municipios metropolizados, Soacha y Fusagasugá, postularon proyectos al programa de vivienda gratuita, lo que es un nuevo síntoma del cierre de los mercados residenciales para hogares pobres en el resto de la Sabana de Bogotá, cuya socia más notable es el recrudecimiento de la segregación socioespacial de escala metropolitana. En los proyectos de mediana y gran envergadura se han acelerado los procesos constructivos y la entrega y los sorteos del SFVE, a fin de cumplir las metas de la administración Santos, algo socialmente deseable a no ser porque en desarrollos de esta naturaleza es indispensable la gestión de la demanda ex ante, por medio de la que se promuevan los valores y las reglas que permitan la cohesión social en los vecindarios, algo que el afán en la ejecución pasó por alto y hoy le plantea serias limitaciones a la convivencia entre los beneficiarios.

\section{Reflexiones finales}

Schmitter (1985) manifestó su desconcierto acerca de las mutaciones acaecidas en el Estado al señalar que este "se ha convertido en algo parecido al tiempo atmosférico" (p. 47). En épocas de intensificación de las anomalías del clima, esto se entiende como algo impredecible y confuso. Pero desconocer qué es el Estado o a que se dedica en los tiempos recientes, no es excusa para olvidar que su origen es, antes que nada, una conquista social, una creación colectiva indispensable para producir un orden social que ningún otro ente por sí mismo podría producir, ni siquiera los mercados, o a pesar de ellos. En relación con el Estado como "la gran construcción institucional de las sociedades", Bresser-Pereira (2009) argumenta que el Estado y sus funciones han sido usurpados por los funcionarios del neoliberalismo, también los mercados.

Los enfoques corporatistas del Estado no se han librado de los debates lingüísticos que pretenden una aclaración nominativa, en relación con el uso alternativo de corporativismo. Al respecto, Solé (1984) concluyó que, más allá de los problemas lingüísticos que entraña y de la ausencia de una definición universalmente aceptada, la trascendencia del corporatismo radica en que "las prácticas corporatistas son recurrentes y progresivamente constitutivas de las relaciones sociales entre los actores principales en las sociedades avanzadas de nuestro tipo" (p. 25). Esta idea es el par dialéctico del pluralismo, un sistema político en el que el Estado es controlado por los diferentes grupos de la sociedad y por ello es capaz de procesar y ponderar las preferencias de los ciudadanos (Dahl, 1971).

Los MISN se adoptaron como una salida intencionada de los miembros de la cadena productiva de la vivienda a la crisis recesiva iniciada en por la banca de inversión en los Estados Unidos. El acuerdo neocorporatista enfrentaba una poderosa limitación consistente en la indisponibilidad de suelo territarias 40

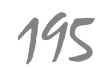


urbanizado y, para ello, el acuerdo optó por transgredir la autonomía municipal en el ordenamiento territorial a fin de construirlos “en cualquier lugar" y someter trámites cruciales como el licenciamiento de los MISN al nuevo arreglo sin respeto a las normas urbanísticas locales. Los promotores del arreglo neocorporatista, que conocían de las demandas de inconstitucionalidad que sobrevendrían, contrataron prestantes figuras del ámbito jurídico para su defensa, quienes, en tal ejercicio, esgrimieron argumentos peregrinos como los de la insuficiencia argumentativa o el de la no contravención de mandato constitucional alguno. La aceleración de los procesos de adopción de los MISN fue la estrategia para que no se presentara "traumatismo alguno", luego de que sobreviniera el fallo de inconstitucionalidad en la que la Corte Constitucional optó por apartarse de un fallo con eficacia jurídica que suspendería la ejecución de los MISN en curso.

Si bien, hay vínculos formales entre los MISN y las metas de la política del SFVE, estos últimos se diferencian por realizarse con arreglo a las normas del ordenamiento territorial municipal; es decir, son desde esta perspectiva el retorno al respeto a la autonomía local y política transgredida por el anterior esquema. Esos vínculos expresan algo en común, que es la discutible calidad de los activos residenciales producidos y entregados a los hogares beneficiarios, fenómeno resultante del afán constructivo para la realización de las metas de los gobiernos, en el que componentes inaplazables, como la gestión de la de- manda requerida para propiciar entornos residenciales amigables y seguros, se juzgan como innecesarios y como obstáculos a la política. Los resultados sociales en aspectos como la convivencia y la inseguridad contradicen tal afán.

En vista de la proliferación de grupos de interés de diversa índole y escala, el Estado colombiano, y el tercermundista en general, seguirá siendo objeto de captura y, por ello, los fines del pluralismo se diluyen hasta tornar abstrusas las formas modernas de intervención estatal, acciones y omisiones encaminadas a gestionar crisis particulares. Se asiste a arreglos aún sin análisis de fondo en órbitas funcionales como la salud pública y la justicia, que constituyen áreas cruciales de investigación, cuyos resultados están llamados a proveer elementos de juicio para la recuperación de la gran conquista societal que es el Estado, a fin de reencaminarlo por la senda del pluralismo.

\section{Referencias}

Abramo, P. (2011). La ciudad caleidoscópica. Coordinación espacial y convención urbana: una perspectiva heterodoxa para la economía urbana. Colección Economía Institucional Urbana, N. ${ }^{\circ}$ 4. Bogotá: Universidad Externado de Colombia.

Acebedo, R. L. F. (2016). Indignación y resistencia contra los macro-proyectos VIS y VIP de San José (Manizales) y San Antonio (Buenaventura). Caleidoscopios Urbanos. Recuperado de http:// caleidoscopiosurbanos.com/indigna- 
cion-y-resistencia-contra-los-macroproyectos-vis-y-vip-de-san-jose-manizales-y-san-antonio-buenaventura/

Alfonso, R. Ó., \& Amézquita, L. (2017). La segmentación del mercado residencial formal en la zona metropolitana en la última década. En Ó. Alfonso (compilador), Bogotá en la encrucijada del desorden: estructuras socioespaciales y gobernabilidad metropolitana (pp. 83120). Colección Economía Institucional Urbana, N. ${ }^{\circ} 13$. Bogotá: Universidad Externado de Colombia.

Alfonso, R. Ó. (2007). Urbanización y desarrollo inmobiliario residencial. En $\mathrm{H}$. Vargas C. (dirección editorial), Cincuenta años en la construcción de Colombia: Camacol 1957-2007(pp. 83-111). Bogotá: CAMACOL.

Alfonso, R. Ó. (2012). Bogotá segmentada: reconstrucción histórico-social de la estructuración residencial de una metrópoli latinoamericana. Colección Economía Institucional Urbana, N. ${ }^{\circ}$ 6. Bogotá: Universidad Externado de Colombia.

Audelo, C. J. M. (s. f.). Sobre el concepto de corporativismo: una revisión en el contexto político mexicano actual. Recuperado de https://archivos.juridicas.unam. mx/www/bjv/libros $/ 4 / 1627 / 5$.pdf

Bresser-Pereira, L. C. (2009). El asalto al Estado y al mercado: neoliberalismo y teoría económica. En Revista Nueva Sociedad, 221. Recuperado de http:// nuso.org/media/articles/downloads/3611_1.pdf
Cawson, A. (1988). Reply to Leo Panitch's Review Article "Corporatism: A Growth Industry Reaches the Monopoly Stage". Canadian Journal of Political Science/ Revue canadienne de science politique, 21(4). Recuperado de http://www. jstor.org/stable/3228905

Cohen, M., Carrizosa, M., \& Gutman M. (Eds.) (2016). Hábitaten deuda: veinte años de politicas urbanas en América Latina. Buenos Aires: Café de las Ciudades-The New School.

Currie, L. (1993). La teoría en que se basa la estrategia del sector líder. Cuadernos de Economía, XIII(18-19), 225-230.

Dahl, R. (1971). Polyarchy: Participation and Opposition. Yale University, New Haven and London. Recuperado de https://caridadmcnallyplea.files.wordpress.com/2017/05/polyarchy-participation-and-opposition-by-robert-adahl.pdf .

Expansión (2014). Sí, la peor Crisis Económica Mundial fue en 2008: Bernanke. Expansión. Recuperado de https://expansion.mx/economia/2014/08/28/ crisis-de-2008-peor-que-la-gran-depresion

Hernández, D. G. (2011). Matrices InsumoProducto y Análisis de Multiplicadores: Una aplicación para Colombia. Archivos de Economía, Documento 373. Bogotá, Departamento Nacional de Planeación. Recuperado de https:// www.economiainstitucional.com/pdf/ No26/ghernandez.pdf.

Jaramillo, S., \& Cuervo, N. (2014). Precios inmobiliarios de vivienda en Bogotá 
1970-2013. En Documento CEDE 2014-18. Bogotá: CEDE - Facultad de Economía, Universidad de los Andes. Recuperado de https://economia. uniandes.edu.co/components/com_ booklibrary/ebooks/dcede2014-18. pdf

Kattan, O. F. (2013). Gremios y gobierno. Recuperado de http://www.elpais. com.co/opinion/columnistas/ode-farouk-kattan/gremios-y-gobierno.html.

Marques-Pereira, B. (1999). "Corporativismo societal" y "corporativismo de Estado": Dos modos de intercambio político. Foro Internacional, 39(1), Recuperado de http://www.jstor.org/ stable $/ 27738933$

Montenegro, A. (2012). Lauchlin Currie: crecimiento y desarrollo económico. Revista Economía Institucional, 14(17), 81-97.

Ortega, R. J. M. (1997). Sobre el desarrollo de la teoría del neocorporativismo. Revista Mexicana de Sociología, 59(4), Recuperado de http://www.jstor.org/ stable/3541123.

Panitch, L. (1988). Corporatism: A Growth Industry Reaches the Monopoly Stage. Canadian Journal of Political Science, 21(4). Recuperado de http://www. jstor.org/stable/3228904

Panitch, L. (1980). Recent Theorizations of Corporatism: Reflections on a Growth Industry. The British Journal of Sociolo$g y, 31(2)$. Recuperado de http://www. jstor.org/stable/589686.
Popper, K. R. (2006). La sociedad abierta y sus enemigos. Serie Surcos. Barcelona: Paidós.

Revéiz, E. (2016). La transgresión moral de las élites y el sometimiento de los Estados. Bogotá: Academia Colombiana de Ciencias Económicas.

Rodríguez, A., \& Rodríguez, P. (2016). Chile: vivienda privada de la ciudad. En Cohen, M.; M. Carrizosa y M. Gutman (editores), Hábitat en deuda: veinte años de politicas urbanas en América Latina (pp. 101-152). Buenos Aires: Café de las Ciudades - The New School.

Rubiano, B. M. (2017). Segregación socioespacial y dinámica metropolitana desde las relaciones Bogotá-Soacha: una reflexión a partir del caso de Ciudad Verde. En M. Rubiano (Compiladora), Segregación socioespacial: miradas cruzadas desde Rio de Janeiro, Bogotá $y$ sus áreas de influencia metropolitana. Recuperado de http://www.unipiloto. edu.co/segregacion-socio-espacial/

Schmitter, Ph. C. (1999). The Future of Democracy: Could It Be A Matter of Scale? Social Research, 66(3). Recuperado de http://www.jstor.org/stable/40971356.

Schmitter, Ph. C. (1985). Neocorporatismo y Estado. Revista Española de Investigaciones Sociológicas, 31. Recuperado de http://www.jstor.org/stable/40183123 (16/12/2017).

Schmitter, Ph. C. (1974). Still the Century of Corporatism? The Review of Politics, 
36(1). Recuperado de http://www. jstor.org/stable/1406080

Solé, C. (1984). El debate corporativismoneocorporatismo. Reis: Revista Española de Investigaciones Sociológicas, 26, Recuperado de http://www.jstor.org/ stable/40183038 (16/12/2017).

Torres, J. E. (2016). Colombia. La singularidad de la política de vivienda en el desarrollo urbano. En Cohen, M.; M. Carrizosa y M. Gutman (eds.), Hábitat en deuda: veinte años de politicas urbanas en América Latina (pp. 205-292). Buenos Aires: Café de las Ciudades-The New School.
Tu, Y. (2003). Housing Economics Public Policy. Oxford: Blackwell Publishing \& RICS Foundation.

Visedo, M. J. (1996). El Estado Corporativo: Italia, una sociedad en crisis. Panta Rei, 11. Recuperado de https://www. um.es/cepoat/pantarei/wp-content/ uploads/2018/04/1996.pdf

Ziccardi, A. (2016). México: de Hábitat II a Habitat III, evaluación de los compromisos asumidos. En M. Cohen, M. Carrizosa y M. Gutman (editores), Hábitat en deuda: veinte años de politicas urbanas en América Latina (pp. 23-100). Buenos Aires, Café de las Ciudades-The New School. 
